\title{
Jenis-Jenis Jamur Makroskopis Anggota Kelas Basidiomysetes di Hutan Bayur, Kabupaten Landak, Kalimantan Barat
}

\section{Basidiomycetes from Bayur Forest, Landak Regency, West Borneo}

\author{
Rahmawati, Linda R, Tanti NY \\ Fakultas Matematika dan Ilmu Pengetahuan Alam Universitas Tanjungpura, Pontianak
}

Rahmawati, Linda R, Tanti NY. 2018 - Jenis-Jenis Jamur Makroskopis Anggota Kelas Basidiomycetes di Hutan Bayur, Kabupaten Landak, Kalimantan Barat. Jurnal Mikologi Indonesia 2 (2): 56-66

\begin{abstract}
Abstrak
Jamur makroskopis dapat dimanfaatkan sebagai bahan makanan dan obat. Pada ekosistem hutan, jamur makroskopis berperan sebagai dekomposer. Penelitian ini bertujuan untuk mengetahui jenis-jenis jamur makroskopis anggota kelas Basidiomycetes yang terdapat di Hutan Bayur, Kabupaten Landak, Kalimantan Barat. Metode yang digunakan dalam penentuan stasiun sampling adalah purposive sampling dengan memilih 3 stasiun berdasarkan perbedaan rona lingkungan. Pengambilan sampel dilakukan dengan metode jelajah (Cruise Method). Identifikasi jamur makroskopis dengan mencocokkan karakteristik morfologis sampel dengan buku identifikasi. Hasil penelitian menunjukkan bahwa ditemukan 18 jenis jamur makroskopis yang termasuk ke dalam empat Ordo, yaitu Aphyllophorales, Agaricales, Auriculariales dan Polyporales. Jamur makroskopis yang ditemukan mendominasi berasal dari Ordo Aphyllophorales, seperti Pycnoporus sanguineus, Polyporus versicolor, Polyporus varius, Schizophyllum commune, Thelephora palmata, Earliella scabrosa, Lignosus rhinocerus, Trametes versicolor, Heterobasidion annosum dan Ganoderma applanatum. Beberapa jenis jamur makroskopis yang dimanfaatkan sebagai bahan makanan oleh masyarakat setempat adalah spesies Auricularia polytricha, Hygrocybe conica, Pleurotus ostreatus dan Schizophyllum commune.
\end{abstract}

Kata kunci - diversitas - Kalimantan - jamur makroskopis - Basidiomycetes

\begin{abstract}
Macroscopic fungi can be utilized as foodstuffs and medicines. This fungal group is very important as decomposers in forest ecosystems. This study was aimed to determine the diversity of macroscopic fungi (Basidiomycetes) in the Bayur Forest, Landak Regency of West Borneo. Specimen collection was conducted using purposive sampling in 3 sampling stations. Fungal identification was conducted using morphological method. This study found 18 species of macrofungi belong to four orders, viz, Aphyllophorales, Agaricales, Auriculariales and Polyporales. Among them, members of the Aphyllophorales were found as dominant fungi. These include Pycnoporus sanguineus, Polyporus versicolor, Polyporus
\end{abstract}

Dikirimkan 22 April 2018, Diterima 31 Oktober 2018, Terbit online 1 Desember 2018

Corresponding Author: Rahmawati - e-mail-rahma_bio02@yahoo.com/rahmawati@fmipa.untan.ac.id 
varius, Schizophyllum commune, Thelephora palmata, Earliella scabrosa, Lignosus rhinocerus, Trametes versicolor, Heterobasidion annosum and Ganoderma applanatum. Several edible fungi were also found such as Auricularia polytricha, Hygrocybe conica, Pleurotus ostreatus and Schizophyllum commune.

Key words - diversity - Kalimantan - macroscopic fungi-Basidiomycetes

\section{Pendahuluan}

Kalimantan Barat memiliki hutan yang kaya akan keanekaragaman jenis organisme, salah satunya adalah jamur makroskopis. Jamur makroskopis adalah jamur sejati yang ukurannya relatif besar (makroskopis) dan dapat dilihat dengan kasat mata, dapat dipegang dan dipetik, serta bentuknya beragam (Gunawan \& Agustin 2001). Jamur makroskopis memiliki beberapa manfaat yang menguntungkan bagi manusia maupun lingkungannya, terutama anggota kelas Basidiomycetes. Menurut Hood (2006), sebagaimana jamur makroskopis lainnya, Basidiomycetes merupakan jamur yang bersifat saprofit dan simbiotik. Jamur tersebut memiliki peranan penting bagi ekosistem hutan sebagai dekomposer. Jamur juga berperan sebagai bahan makanan organisme lainnya yang terdapat di dalam hutan seperti serangga, serta ada juga yang parasit. Jamur ini dapat ditemukan di hutan pada substrat tanah, serasah, atau kayu. Spesies anggota Basidiomycetes telah diketahui mencapai 23.000 spesies. Bahrun dan Muchroji (2005) menyatakan bahwa jamur makroskopis anggota kelas Basidiomycetes ada yang dapat dimanfaatkan sebagai bahan makanan, berkhasiat obat dan ada juga jamur yang menyebabkan keracunan.

Jamur makroskopis di Kalimantan Barat memiliki jenis yang beragam, hal ini dikarenakan wilayah Kalimantan Barat yang dilalui garis khatulistiwa dengan kelembaban tinggi yang menjadi salah satu faktor lingkungan yang mendukung bagi pertumbuhan jamur makroskopis, namun jenis jamur makroskopis yang beragam tersebut belum semua teridentifikasi. Keberadaan jenis jamur makroskopis penting untuk diketahui dan dipelajari serta perlu dilakukan konservasi.

Hutan Bayur di Kabupaten Landak terbagi menjadi dua bagian, yaitu hutan primer dan hutan sekunder. Masyarakat memanfaatkan Hutan Bayur untuk aktivitas perladangan, penebangan pohon dan pembukaan lahan untuk kelapa sawit dan karet sehingga dapat mengurangi keberadaan jamur makroskopis karena berkurangnya pohon-pohon yang mengakibatkan banyaknya cahaya matahari yang masuk ke lantai hutan. Hingga saat ini belum ada informasi tentang data jenis-jenis jamur makroskopis anggota Basidiomycetes yang terdapat di Hutan Bayur sehingga perlu dilakukan penelitian.

Penelitian ini bertujuan untuk mengetahui jenis-jenis jamur makroskopis anggota Basidiomycetes yang terdapat di Hutan Bayur, Kabupaten Landak, Kalimantan Barat. Penelitian ini diharapkan dapat digunakan sebagai informasi awal untuk konservasi sumber daya alam khususnya jamur makroskopis di Hutan Bayur.

\section{Metoda Penelitian}

\section{Penentuan batasan stasiun sampling}

Stasiun pengambilan sampel ditentukan berdasarkan metode purposive sampling dengan melihat kondisi lingkungan yang ada di Hutan Bayur. Penentuan lokasi di Hutan Bayur berdasarkan 3 stasiun dengan perbedaan rona lingkungan (Tabel 1 dan Gambar 1).

\section{Koleksi sampel jamur makroskopis}

Pengambilan sampel dilakukan dengan metode jelajah atau Cruise Method (Rugayah \& Pratiwi, 2004), yaitu dengan menjelajahi tiga stasiun penelitian yang telah ditentukan pada Hutan Bayur yang memiliki rona lingkungan berbeda (Gambar 1). 
Tabel 1 Deskripsi setiap stasiun penelitian

\begin{tabular}{|c|c|c|}
\hline Stasiun & Titik Koordinat & Rona Lingkungan \\
\hline $\mathrm{I}$ & $\begin{array}{l}\text { LS : 00032'04.3” } \\
\text { BT : } 109^{0} 47^{\prime} 32.0^{\prime \prime}\end{array}$ & $\begin{array}{l}\text { Hutan dekat dengan pemukiman warga, hutan } \\
\text { sekunder, kondisi vegetasi pohon kurang rapat, } \\
\text { terdapat pepohonan seperti durian, mangga dan } \\
\text { rambutan }\end{array}$ \\
\hline II & $\begin{array}{l}\text { LS : } 00^{0} 32^{\prime} 18.4^{\prime \prime} \\
\text { BT : 109047'53.7' }\end{array}$ & $\begin{array}{l}\text { Hutan primer, masih dalam keadaan alami, vegetasi, } \\
\text { pohon rapat, banyak daun mati, hutan ternaungi dan } \\
\text { lembab }\end{array}$ \\
\hline III & $\begin{array}{l}\text { LS : } 00^{0} 32^{\prime} 30.2^{\prime \prime} \\
\text { BT }: 109^{0} 47^{\prime} 51.0^{\prime \prime}\end{array}$ & $\begin{array}{l}\text { Hutan sekunder,vegetasi pohon terbuka, untuk lahan } \\
\text { perkebunan sawit dan karet }\end{array}$ \\
\hline
\end{tabular}

Keterangan : LS (Lintang Selatan) dan BT (Bujur Timur)

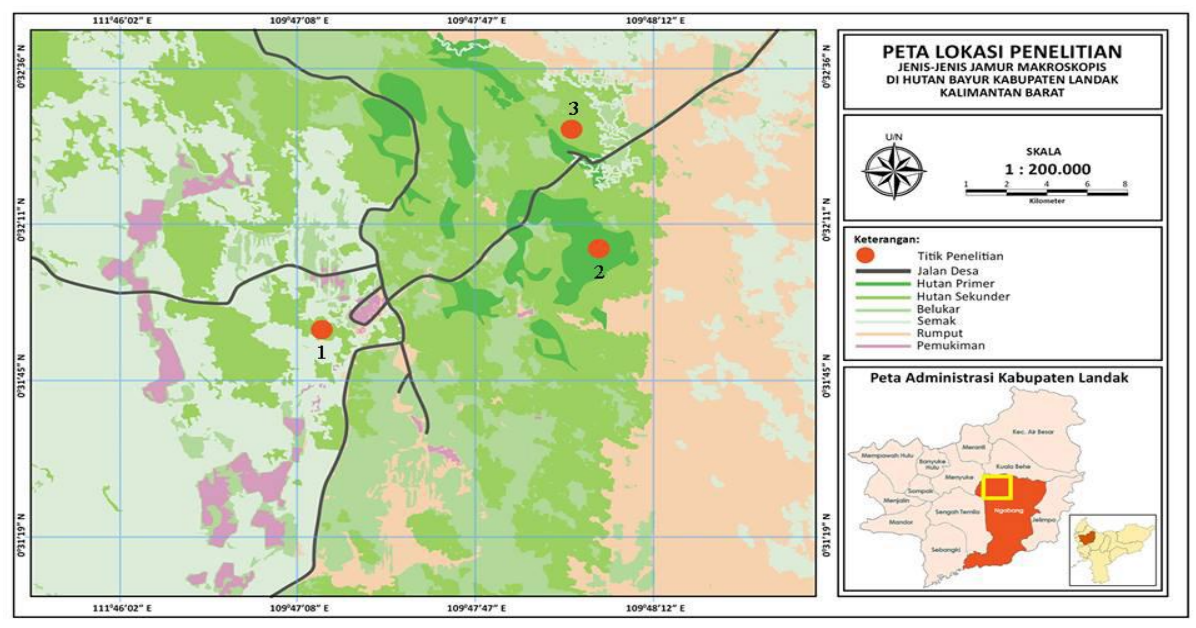

Gambar 1 Peta Stasiun Penelitian (Sumber: Tanti et al. 2018)

\section{Pengamatan karakter morfologi jamur makroskopis}

Pengamatan jamur makroskopis meliputi karakteristik morfologis jamur yaitu warna tubuh jamur, bentuk tudung, bentuk permukaan tudung, bentuk tepi tudung, diameter tudung, bentuk bilah, ada tidaknya tangkai, letak tangkai (jika terdapat tangkai), panjang tangkai, warna tangkai dan tekstur jamur.

\section{Pengukuran parameter lingkungan}

Pengukuran faktor lingkungan meliputi jenis substrat, suhu, kelembaban, intensitas cahaya dan tingkat keasaman substrat $(\mathrm{pH})$. Data pengukuran faktor lingkungan pada saat pengambilan sampel dilapangan dilakukan dari pagi sampai sore hari.

\section{Identifikasi jenis jamur makroskopis}

Sampel diidentifikasi menggunakan buku "Edible And Poisonous Mushroom of The World" oleh Hall et al. (2003), "A Field Guide to Edible And Inedible Fungi North American Mushrooms" oleh Miller dan Miller (2006), dan" Introduction to Fungi" oleh Webster dan Weber (2007), "Mushroom and Other Fungi of the Midcontinental United States" oleh Huffman et al. (2008), serta berbagai artikel jurnal ilmiah mengenai jamur makroskopis. 


\section{Pembuatan Herbarium dan kunci determinasi}

Pembuatan herbarium terdiri atas herbarium basah dan kering. Kunci determinasi yang dipakai adalah kunci dikotom (bercabang dua).

\section{Analisis data}

Data hasil pengamatan dianalisis secara kualitatif, dan disajikan dalam bentuk dokumentasi (foto) dan tabel.

\section{Hasil}

Berdasarkan hasil penelitian, pada stasiun satu ditemukan 2 Ordo anggota kelas Basidiomycetes yang terdiri atas 5 familia dan 8 spesies. Hasil penelitian pada stasiun dua ditemukan 2 Ordo dari kelas Basidiomycetes yang terdiri atas 3 familia dan 3 spesies. Hasil penelitian pada stasiun 3 ditemukan 3 Ordo anggota kelas Basidiomycetes yang terdiri atas 5 familia dan 7 spesies (Tabel 2 dan Gambar 2). Jamur makroskopis yang mendominasi berasal dari bangsa Aphyllophorales sebanyak 10 jenis dan yang paling sedikit ditemukan adalah anggota bangsa Auriculariales dan bangsa Polyporales, masing-masing 1 jenis.

Tabel 2 Jenis-Jenis Jamur Makroskopis kelas Basidiomycetes di Hutan Bayur, Kabupaten Landak, Kalimantan Barat

\begin{tabular}{|c|c|c|c|c|}
\hline Stasiun & Ordo & Familia & Spesies & Substrat \\
\hline $\mathrm{I}$ & Aphyllophorales & $\begin{array}{l}\text { Schizophyllaceae } \\
\text { Thelephoraceae } \\
\text { Marasmiaceae } \\
\text { Tricholomataceae }\end{array}$ & $\begin{array}{l}\text { Pycnoporus sanguineus } \\
\text { Polyporus versicolor } \\
\text { Polyporus varius } \\
\text { Schizophyllum commune } \\
\text { Thelephora palmata } \\
\text { Marasmiellus candidus } \\
\text { Marasmiellus perforans } \\
\text { Pleurotus ostreatus }\end{array}$ & $\begin{array}{l}\text { Pohon mati } \\
\text { Pohon mati } \\
\text { Pohon mati } \\
\text { Pohon mati } \\
\text { Tanah } \\
\text { Pohon mati } \\
\text { Serasah } \\
\text { Pohon mati }\end{array}$ \\
\hline II & $\begin{array}{l}\text { Agaricales } \\
\text { Auriculariales }\end{array}$ & $\begin{array}{l}\text { Clavariaceae } \\
\text { Hygrophoraceae } \\
\text { Auriculariaceae }\end{array}$ & $\begin{array}{l}\text { Clavulinopsis } \\
\text { corallinorosacea } \\
\text { Hygrocybe conica } \\
\text { Auricularia polytricha }\end{array}$ & $\begin{array}{l}\text { Tanah } \\
\text { Tanah } \\
\text { Pohon mati }\end{array}$ \\
\hline III & $\begin{array}{l}\text { Agaricales } \\
\text { Polyporales }\end{array}$ & $\begin{array}{l}\text { Bondarzewiaceae } \\
\text { Ganodermataceae } \\
\text { Cortinariaceae } \\
\text { Meripilaceae }\end{array}$ & $\begin{array}{l}\text { Earliella scabrosa } \\
\text { Lignosus rhinoceros } \\
\text { Trametes versicolor } \\
\text { Heterobasidion annosum } \\
\text { Ganoderma applanatum } \\
\text { Cortinarius rotundisporus } \\
\text { Rigidoporus microporus }\end{array}$ & $\begin{array}{l}\text { Pohon mati } \\
\text { Pohon mati } \\
\text { Pohon mati } \\
\text { Pohon mati } \\
\text { Pohon mati } \\
\text { Tanah } \\
\text { Pohon mati }\end{array}$ \\
\hline
\end{tabular}



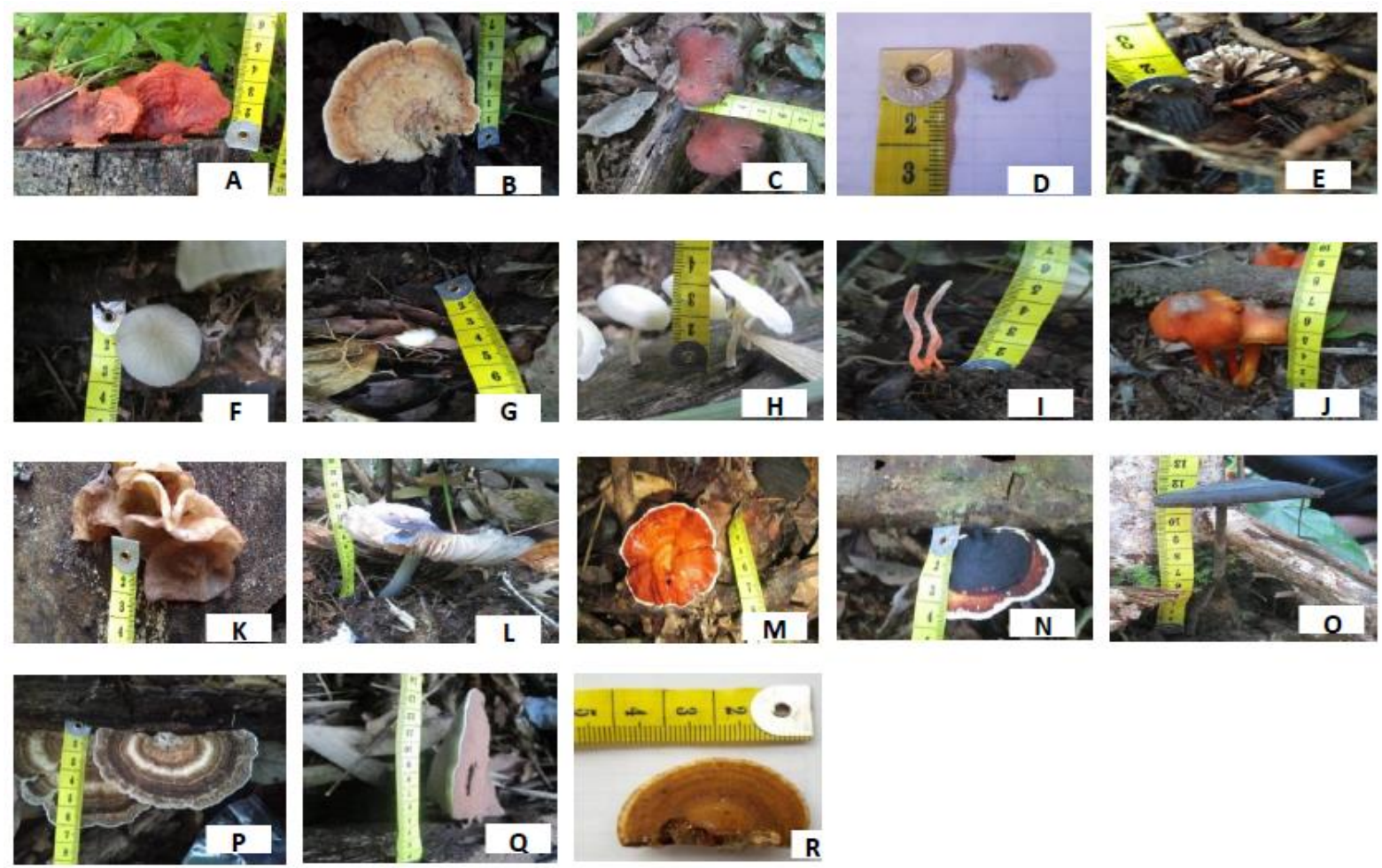

Gambar 2 Jenis-Jenis Jamur Makroskopis yang ditemukan di Hutan Bayur, Kabupaten Landak, Kalimantan Barat (A) Pycnoporus sanguineus, (B) Polyporus versicolor, (C) Polyporus varius, (D) Schizophyllum commune, (E) Thelephora palmata, (F) Marasmiellus candidus, (G) Marasmiellus perforans, (H) Pleurotus ostreatus, (I) Clavulinopsis corallinorosacea, (J) Hygrocybe conica, (K) Auricularia polytricha, (L) Cortinarius rotundisporus, (M) Rigidoporus microporus, (N) Earliella scabrosa, (O) Lignosusrhinocerus, (P) Trametes versicolor, (Q) Heterobasidion annosum, (R) Ganoderma applanatum

\section{Kunci determinasi jamur makroskopis yang ditemukan:}

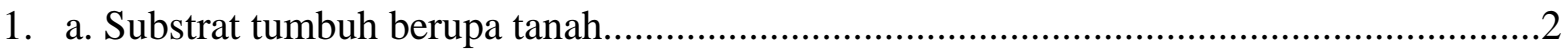

b. Substrat tumbuh berupa pohon mati atau daun mati....................................................6

2. a. Jamur tidak memiliki tangkai,bentuk tudung seperti karang, warna oranye keputihan, bentuk tepi tudung halus, tidak bergaris,tekstur berdaging...........Clavulinopsis corallinorosacea

b. Jamur memiliki tangkai, bentuk tudung tidak seperti diatas

3. a. Letak tangkai (lateral), bilah beralur, terkstur kulit,bentuk tudung kipas....Thelephora palmata

b. Letak tangkai (central), bilah teratur, tekstur lunak, bentuk tudung bukan kipas......5

5. a. Bentuk tudung payung, tepi tudung menggulung keluar, tangkai berwarna putih kebiru-biruan. Cortinarius rotundisporus

b. Bentuk tudung kerucut, tepi tudung terbelah, tangkai berwarna oranye pada ujung tangkai pangkal tangkai berwarna puti. Hygrocybe conica

6. a. Bentuk tudung payung dan permukaan tudung berfibril..Genus: Marasmiellus..........7

b. Bentuk tudung tidak payung dan permukaan tidak berfibril 
7. a. Letak tangkai (eccentric), bentuk bilah bercabang ketepi (margin

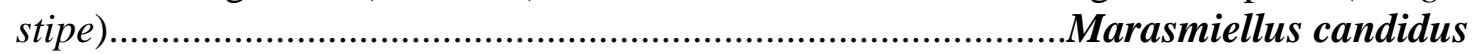

b. Letak tangkai (central), bilah memiliki bentuk teratur atau tertata

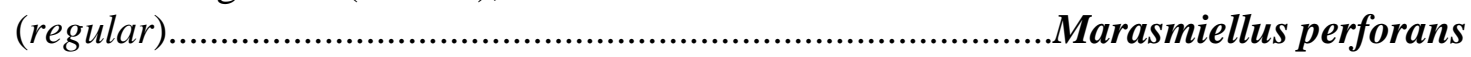

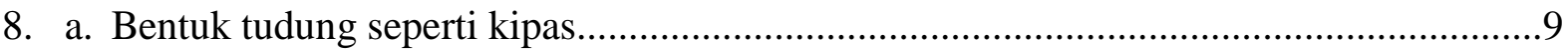

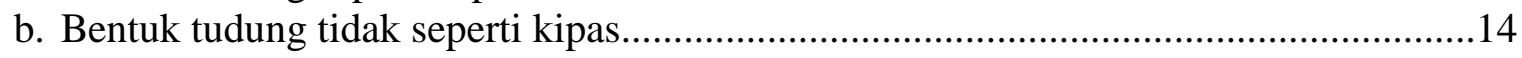

9. a. Bentuk bilah bercabang ke tepi,bilah berwarna abu-abu, tekstur berdaging, tudung berwarna abu-abu, permukaan tudung berbulu panjang.... ...Schizophyllum commune

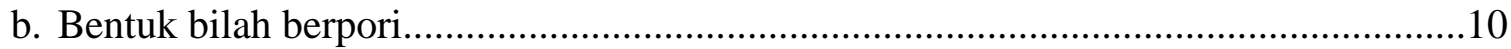

10. a. Bilah berwarna coklat, tudung berwarna coklat polos (Genus:

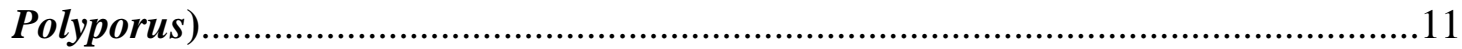

b. Bilah berwarna hitam atau putih, warna tudung tidak berwarna coklat, jika berwarna coklat tepi tudung berwarna putih............................................................. 12

11. a. Permukaan tudung halus dan tidak bergaris, memiliki tangkai letak tangkai (lateral), berwarna coklat dan tepi tudung berlekuk.........................................Polyporus varius

b. Permukaan tudung berkerut, jamur tidak memiliki tangkai dan tepi tudung berlekuk........................................................................................Polyporus versicolor

12. a. Tekstur tubuh buah keras seperti kayu, memiliki tangkai, letak tangkai (central), permukaan tudung berkerut, warna tudung kuning, coklat dan di tepi tudung berwarna putih.

Rigidoporus microporus

b. Tekstur tubuh buah kulit, tidak memiliki tangkai, permukaan tudung tidak seperti

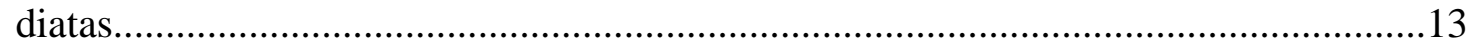

13. a. Permukaan tudung kasar dan bergelombang, warna tudung hitam, merah dan putih.

Earliella scabrosa

b. Permukaan tudung berbulu sangat rapat, warna tudung coklat dan warna putih ditepi tudung.

Trametes versicolor

14. a. Bentuk tudung setengah lingkaran, permukaan tudung berbutir kasar dan tudung berwarna coklat dan putih di tepi tudung, bilah berpori, bilah berwarna

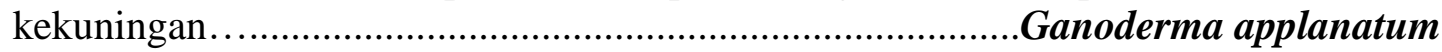

b. Bentuk tudung payung terbalik, permukaan tudung halus dan tudung berwarna putih keabu-abuan, bilah teratur, bilah berwarna

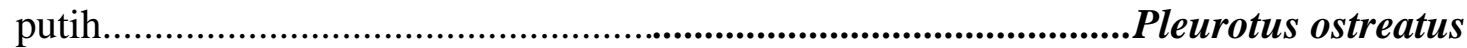

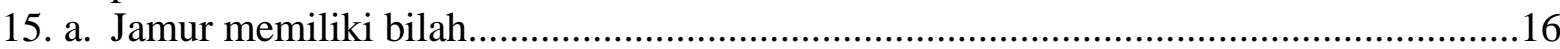

b. Jamur tidak memiliki bilah, bentuk tudung bergelombang seperti kuping, permukaan tudungberkerutdanlicin,bentuktepitudungbergelombang dan tidak teratur.........................................................................................uricularia polytricha

16. a. Bentuk bilah berpori berwarna hitam, tekstur tubuh buah keras,bentuk tepi tudung tidak rata, bentuk tudung lebar.

Lignosus rhinoceros

b. Bentuk bilahberpori berwarna oranye atau putih,tekstur tubuh buah tidak seperti diatas bentuktepitudung sedikit berlekuk.

17. a. Bentuk bilah berpori berwarna oranye tekstur tubuh buah kulit permukaan tudung halus, bentuk tudung setengah lingkaran, tudung jamur berwarna oranye.

Pycnoporus sanguineus

b. Bentuk bilah berpori berwarna putih, tekstur tubuh buah seperti kayu, permukaan tudung tidak rata dan licin, bentuk tudung cembung melebar, tudung jamur berwarna coklat dan putih di bagian tepi tudung. Heterobasidion annosum

Hasil pengukuran faktor lingkungan di Hutan Bayur, Kabupaten Landak Kalimantan Barat menunjukkan bahwa suhu berkisar antara $27-31^{\circ} \mathrm{C}$, kelembaban $70-85 \%$, intensitas cahaya 332-850 Lux, dan pH substrat 6-6,8 (Tabel 3). 
Tabel 3 Faktor Lingkungan di Hutan Bayur Kabupaten Landak Kalimantan Barat

\begin{tabular}{lllll}
\hline Stasiun & Suhu $\left({ }^{\circ} \mathbf{C}\right)$ & Kelembaban $(\%)$ & Intensitas Cahaya (Lux) & pH Substrat \\
\hline I & 27 & 73 & 450 & 6 \\
II & 23 & 85 & 332 & 6,8 \\
III & 31 & 70 & 850 & 6,5 \\
\hline
\end{tabular}

\section{Pembahasan}

Jamur makroskopis yang ditemukan di Hutan Bayur terdiri atas anggota Ordo Aphyllophorales, Agaricales, Auriculariales dan Polyporales yang termasuk ke dalam anggota kelas Basidiomycetes. Jamur makroskopis tersebut ada yang tumbuh pada substrat daun mati, pohon mati dan tanah. Hal ini dikarenakan substrat tersebut merupakan substrat yang cocok untuk pertumbuhan jamur. Menurut Suhardiman (1995), jamur makroskopis anggota kelas Basidiomycetes dapat tumbuh pada lingkungan yang mengandung sumber karbohidrat, selulosa dan lignin yang terdapat pada serasah, tanah dan kayuyang sudah lapuk yang digunakan sebagai sumber nutrisi bagi pertumbuhan jamur makroskopis. Noverita et al. (2017) menyatakan bahwa jamur makroskopis pada umunya hidup sebagai saprofit di habitat asalnya dan berperan sebagai pengurai bahan-bahan organik mati seperti kayu mati atau kayu lapuk dan serasah. Hal ini menunjukkan bahwa jamur yang ditemukan bersifat saprofit dan heterotrof.

Berdasarkan hasil penelitian (Tabel 2 dan Gambar 2), jamur makroskopis yang mendominasi berasal dari anggota Ordo Aphyllophorales yang terdiri dari lima familia dan sepuluh spesies. Hal ini dikarenakan anggota kelompok Aphyllophorales mempunyai kemampuan adaptasi yang lebih baik dibandingkan dengan anggota Ordo Agaricales, Polyporales, maupun Auriculariales (Al Ulya et al. 2017). Jamur anggota Ordo Aphyllophorales yang ditemukan tumbuh pada substrat pohon mati dan di tanah karena substrat tersebut mengandung sumber nutrisi untuk pertumbuhannya. Hal ini sesuai dengan pernyataan Suhardiman (1995) bahwa anggota Bangsa Aphyllophorales merupakan kelompok jamur yang memiliki banyak spesies, dan mudah dijumpai karena kelompok jamur ini tumbuh pada berbagai substrat seperti substrat kayu, serasah dan tanah serta mampu beradaptasi pada kondisi lingkungan yang tidak mendukung pertumbuhannya. Jamur anggota Ordo Aphyllophorales memiliki spesies yang cukup banyak berasal dari familia Polyporaceae. Menurut Tampubolon et al. (2012), anggota familia Polyporaceae memiliki tubuh buah yang besar sehingga memiliki kemampuan untuk beradaptasi dengan baik di berbagai lingkungan dan jamur dari anggota familia Polyporaceae mampu bertahan hidup pada kondisi yang kering.

Jamur anggota Ordo Agaricales merupakan Ordo yang memiliki anggota spesies paling banyak setelah anggota Ordo Aphyllophorales. Menurut Tampubolon et al. (2012), anggota Ordo Agaricales merupakan kelompok jamur yang sering ditemukan dengan bentuk seperti payung. Hawksworth (1990) menyatakan bahwa anggota Ordo Agaricales merupakan jamur makroskopis yang memiliki bilah. Jamur anggota familia Marasmiaceae dari Ordo Agaricales yang ditemukan di Hutan Bayur Kabupaten Landak juga memiliki bentuk seperti payung dan memiliki bilah. Jamur yang ditemukan di Hutan Bayur dari anggota familia Marasmiaceae adalah anggota spesies Marasmiellus candidus yang tumbuh pada substrat pohon mati, dan anggota spesies Marasmiellus perforans tumbuh pada serasah. 
Jamur anggota Ordo Auriculariales yang ditemukan di Hutan Bayur terdiri atas satu spesies yaitu spesies Auricularia polytricha yang tergolong famili Auriculariaceae. Arini dan Christita (2016) menyatakan bahwa pada umumnya anggota famili Auriculariaceae memiliki tubuh buah seperti telinga, permukaannya licin, berwarna cokelat, tidak memiliki tangkai, dan hidup berkelompok menempel pada substrat pohon mati. Karakter tersebut sesuai dengan karakter jamur anggota spesies Auricularia polytricha yang ditemukan di Hutan Bayur.

Jamur anggota Ordo Polyporales yang ditemukan di Hutan Bayur, terdiri atas satu spesies, yaitu spesies Rigidoporus microporus yang tergolong anggota familia Meripilaceae. Jamur ini ditemukan hidup berkelompok pada kayu mati. Aryani (2013) menyatakan bahwa jamur anggota genus Rigidoporus memiliki tubuh buah berbentuk seperti kipas, dengan tekstur keras seperti kayu, terdapat garis konsentris, memiliki tangkai dan hidup berkelompok pada substrat pohon mati.

Masyarakat di sekitar Hutan Bayur memanfaatkan beberapa jenis jamur sebagai bahan makanan, yaitu anggota spesies Auricularia polytricha, Pleurotus ostreatus, Schizophyllum commune, dan Hygrocybe conica. Hal ini sesuai dengan pendapat Hall et al. (2003) dan hasil penelitian yang dilakukan oleh Tarsia (2010), dan Chotimah et al. (2011), yang menyatakan bahwa jamur-jamur jenis tersebut merupakan jamur yang dapat dikonsumsi (edible mushroom). Al Ulya et al. (2017) juga menyatakan bahwa jamur kuping atau anggota genus Auricularia sering dimanfaatkan sebagai sumber makanan dikarenakan memiliki rasa yang lezat dan bergizi.

Jamur yang ditemukan di Hutan Bayur, ada yang tidak ditemukan pada beberapa sumber penelitian yang telah dipublikasikan di Kalimantan Barat. Perbedaan ini diduga karena faktor lingkungan, seperti suhu. Suhu di lokasi penelitian rata-rata berkisar antara 27-31 ${ }^{\circ} \mathrm{C}$ (Tabel 3), sedangkan pada penelitian yang dilakukan oleh Wahyudi (2012) di Kubu Raya memiliki suhu rata-rata berkisar $28-29^{\circ} \mathrm{C}$. Selain itu, penelitian Sariet al. (2015) di Kapuas Hulu dengan suhu rata-rata berkisar $27-32^{\circ} \mathrm{C}$, serta hasil penelitian Tarsia (2010) di Landak dan Anggraini et al. (2015) di Sanggau dengan suhu rata-rata berkisar $27-29^{\circ} \mathrm{C}$, yang tidak menemukan jamur anggota spesies Collybia dryophila, Stereum hirsitum, Iscnoderma benzoinum, Lentinus lepideus, Oudemansiella canarii, Tremella foliacea, Tremella fuciformis dan Cantharella cibarius. Hal ini sesuai dengan pernyataan Suriawiria (1986), bahwa pertumbuhan jamur dipengaruhi oleh faktor lingkungan yang berbeda di setiap daerah. Perbedaan suhu $0,1^{\circ} \mathrm{C}$ dapat mempengaruhi kelangsungan kehidupan jamur, selain itu lingkungan biotik dan abiotik yang lain juga berpengaruh sangat besar terhadap kehidupan jamur. Perbedaan jenis jamur juga dikarenakan faktor kelembaban di lokasi penelitian ini cukup tinggi, yaitu di atas 70\% (Tabel 3), berbeda dengan kelembaban di lokasi penelitian jamur makroskopis yang dilakukan oleh Noverita et al. (2017), yaitu di kawasan cagar alam yang ada di Sumatera Barat, kelembabannya berkisar antara 40-65\%. Beberapa jamur makroskopis yang ditemukan di kawasan cagar alam tersebut tidak ditemukan di Hutan Bayur ini. Chang dan Milles (2004) cit. Noverita et al. (2017) menyatakan bahwa pertumbuhan maksimal sebagian besar jamur makroskopis anggota filum Basidiomycota berkisar pada kadar air 50-70\%.

Jenis-jenis jamur makroskopis yang ditemukan pada masing-masing stasiun berbeda. Hal ini disebabkan oleh perbedaan kondisi vegetasi yang ada pada hutan primer dan hutan sekunder. Jamur anggota Bangsa Aphyllophorales ditemukan pada stasiun satu dan tiga yang merupakan hutan sekunder dengan vegetasi pohon terbuka dan tidak ditemukan pada stasiun dua yang merupakan hutan primer dengan vegetasi pohon tertutup. Hal ini dikarenakan faktor lingkungan yang berbeda antara hutan primer dan hutan sekunder.

Berdasarkan hasil penelitian yang telah dilakukan di Hutan Bayur, Kabupaten Landak, Kalimantan Barat, dapat disimpulkan bahwa ditemukan 18 jenis jamur makroskopis anggota kelas Basidiomycetes yang terdiri atas 4 Ordo dan 12 familia pada 3 stasiun penelitian. Jamur makroskopis yang paling banyak ditemukan barasal dari anggota Bangsa Aphyllophorales. 
Jamur makroskopis yang ditemukan sebagian besar tumbuh pada substrat pohon yang sudah mati.

\section{Ucapan Terima Kasih}

Terima kasih disampaikan kepada masyarakat di sekitar Hutan Bayur, Kabupaten Landak, Kalimantan Barat, khususnya kepada Bapak Suparno yang merupakan kepala desa di Dusun Sungai Durian Kabupaten Landak, serta teman-teman (Dendi Irawan dan Salomon), yang telah membantu pengambilan sampel di lapangan.

\section{Pustaka}

Al Ulya AN, Leksono SM, Khastini RO. 2017 - Biodiversitas dan Potensi Jamur Basidomycota di Kawasan Kasepuhan Cisungsang, Kabupaten Lebak, Banten. AL KAUNIYAH: Journal of Biology 10(1), 9-16

Anggraini K, Khotimah S, Turnip M. 2015 - Jenis-Jenis Jamur Makroskopis di Hutan Hujan Mas Desa Kawat Kecamatan Tayan Hilir Kabupaten Sanggau. Jurnal Protobiont 4(3), 60-64.

Arini DID, Christita M. 2016 - Keanekaragaman Makrofungi di Cagar Alam Gunung Ambang Sulawesi Utara dan Peluang Potensinya. Proceeding Seminar Nasional Biodiversitas VI. Surabaya.

Aryani. 2013 - Identifikasi Jamur di Kebun Raya Bukit Sari: Skripsi. Jurusan PMIPA FKIP. Universitas Jambi.

Bahrun M. 2005 - Bertanam Jamur Merang. PT. Musi Perkasa Utama. Jakarta.

Chotimah HENC, Kresnanita S, Miranda Y. 2011 - Studi Etnobotani Sayuran Indigenous (Lokal) Kalimantan Tengah, Seminar Nasional : Reformasi Pertanian Terintegrasi Menuju Kedaulatan Pangan. Fakultas Pertanian, Universitas Trunojoyo.

Gunawan AW. 2001 - Usaha Pembibitan Jamur. Penebar Swadaya. Jakarta.

Hall IR, Stephenson SL, Buchanan PK, Yun W, Cole ALJ. 2003 - Edible and Poisonous Mushroom of The World. Timber Press, Portland, Cambridge.

Hawksworth D. 1990. The fungal dimension of biodiversity, Magnitude, Significance and conversation. Mycological Research 95, 641-655.

Hood IA. 2006 - The Mycology of the Basidiomycetes. In: ACIAR Proceedings No. 124. Canberra.

Huffman DM, Tiffany LH, Knaphus G, Healy R.A - Mushroom and Other Fungi of the Midcontinental United States, Second Edition, The University of Lowa Press.

Miller OK, JR Miller, HH. 2006 - A Field Guide To Edible And Inedible Fungi North American Mushrooms, Falcon Guide, U.S of America.

Noverita, Sinaga E, Setia TM. 2016 - Jamur Makro Berpotensi Pangan dan Obat di Kawasan Cagar Alam Lembah Anai dan Cagar Alam Batang Palupuh Sumatera. Jurnal Mikologi Indonesia 1(1), 15-27

Rugayah W, Pratiwi. 2004 - Pedoman Pengumpulan Data Keanekaragaman Flora. Pusat Penelitian Biologi LIPI, Bogor.

Sari IM, Linda R, Khotimah S. 2015 - Jenis-Jenis Jamur Basidiomycetes di Hutan Bukit Beluan Kecamatan Hulu Gurung Kabupaten Kapuas Hulu. Jurnal Protobiont 4(1), 2228.

Suhardiman P. 1995 - Jamur Kayu. Penebar Swadaya, Jakarta.

SuriawiriaHU. 1986 - Pengantar untuk Mengenal dan Menanam Jamur, Angkasa, Bandung.

Tanti NY, Rahmawati, Linda R. 2018 - Jenis-Jenis Jamur Makroskopis Anggota Kelas Ascomycetes Di Hutan Bayur Kabupaten Landak Kalimantan Barat. Jurnal Protobiont. $7(1), 38-44$ 
Tampubolon MB, Utomo B, Yunasfi. 2012 - Keanekaragaman jamur makroskopis di hutan pendidikan Universitas Sumatera Utara Desa Tongkoh Kabupaten Karo Sumatera. Saintia Biologi 2, 176-182.

Tarsia D. 2010 - Inventarisasi Jenis Jamur Kayu di Hutan Gunung Semahung Dusun Petai Kecamatan Sengah Temila Kabupaten Landak. Skripsi. Fakultas Matematika dan Ilmu Pengetahuan Alam Universitas Tanjungpura, Pontianak.

Wahyudi AE, Linda R, Khotimah S. 2012,--,Inventarisasi Jamur Makroskopis di Hutan Rawa Gambut Desa Teluk Bakung Kecamatan Sungai Ambawang Kabupaten Kubu Raya. Protobiont 1(1), 8-11.

Webster J, Weber RW. 2007 - Introduction to Fungi. Cambridge University Press, New York. 